\title{
Targeting Purinergic Signaling in the Dynamics of Disease Progression in Sepsis
}

\author{
Raíssa Leite-Aguiar ${ }^{\dagger}$, Vinícius Santos Alves ${ }^{\dagger}$, Luiz Eduardo Baggio Savio* and \\ Robson Coutinho-Silva* \\ Laboratory of Immunophysiology, Biophysics Institute Carlos Chagas Filho, Federal University of Rio de Janeiro, Rio de Janeiro, \\ Brazil
}

Keywords: systemic inflammation, CD39, adenosine, immunosuppression, P2X7 receptor

\section{INTRODUCTION}

Sepsis is an infection-related syndrome that encompasses distinct conditions in which organ dysfunctions are the main features, resulting from imbalances of host immune responses that can be lethal (Singer et al., 2016). Despite advances in supportive treatments, no specific drug has been explicitly approved for treatment of sepsis. For this reason, sepsis remains a health concern worldwide (Reinhart et al., 2017), accounting for the majority of nosocomial deaths, a statistic that is especially worrisome in developing countries (Rudd et al., 2020). The absence of appropriate treatments still remains a major obstacle.

The pathophysiology of sepsis usually begins with excessive and uncontrolled immune responses to a pathogen with the overlapping secretion of both pro- and anti-inflammatory components, culminating in organ failure (Hotchkiss et al., 2013a; Van Der Poll et al., 2017). Over time, this initial hyperinflammatory state gives way to a dominant hypoinflammatory period (Wiersinga et al., 2014; Van Der Poll et al., 2017). During this second stage, there is a depletion of cytokines, combined with induction of inhibitory signaling molecules and apoptosis or reprogramming of inflammatory cells, resulting in transition to an immunosuppressive state, most recently referred to as a state of circulating leukocyte reprogramming (Boomer et al., 2011; Cavaillon et al., 2020). The host's mechanisms to dampen excessive inflammation may interfere with the clearance of infectious organisms or may lead to increased host susceptibility to secondary infections, especially by opportunistic pathogens. In addition, the cellular reprogramming may lead to the development of late sequelae in survivors of sepsis (Otto et al., 2011; Hotchkiss et al., 2013b).

Danger-associated molecular patterns (DAMPs), including adenosine triphosphate (ATP), can be released by activated or damaged cells in the extracellular milieu during infectious conditions including sepsis (Cauwels et al., 2014; Idzko et al., 2014; Sumi et al., 2014). Extracellular ATP (eATP) acts as a danger signal molecule (Coutinho-Silva and Ojcius, 2012; Ma et al., 2018), triggering purinergic signaling, which affects immune cell function and influences the initial hyperinflammatory phase of sepsis (Ledderose et al., 2016). Purinergic signaling is a wellconserved system throughout evolution; the pathway includes purinergic receptors, nucleotides, nucleosides, and ectoenzymes called ectonucleotidases that regulate the metabolism of these molecules (Burnstock and Verkhratsky, 2009; Alves et al., 2020). Regarding its composition and ligand affinity, the purinergic receptors are divided into the metabotropic $P 1$ receptors $\left(A_{1}, A_{2 A}, A_{2 B}\right.$, and $\mathrm{A}_{3}$ ) associated with adenosine $(\mathrm{ADO})$, ionotropic $\mathrm{P} 2 \mathrm{X}$ receptors (P2X1-7), and metabotropic $\mathrm{P} 2 \mathrm{Y}$ receptors $\left(\mathrm{P} 2 \mathrm{Y}_{1}, \mathrm{P}_{2} \mathrm{Y}_{2}, \mathrm{P}_{4} \mathrm{Y}_{4}, \mathrm{P}_{2} \mathrm{Y}_{6}\right.$, and $\left.\mathrm{P} 2 \mathrm{Y}_{11-14}\right)$ for tri- and diphosphonucleotides (Ralevic and Burnstock, 1998; Fredholm et al., 2011; Jacobson et al., 2020). These receptors have distinct roles in inflammatory environments; for example P1 receptors in general can mitigate inflammation and tissue injury, while $\mathrm{P} 2$ receptors can stimulate pro-inflammatory responses and promote bacterial 
killing (Savio et al., 2018; Antonioli et al., 2019; Savio and Coutinho-Silva, 2019). The cleavage of nucleotides occurs mainly through the action of E-NTPDase1/CD39 and ecto-5' nucleotidase/CD73. The former enzyme catalyzes the hydrolysis of adenosine triphosphate (ATP) and adenosine diphosphate (ADP) into adenosine monophosphate (AMP), and the latter catalyzes the hydrolysis of AMP to ADO (Robson et al., 2006). The purinergic signaling has been studied in the sepsis context. Here, we discuss advances in understanding this signaling in sepsis pathophysiology as well as possible therapeutical interventions based on purinergic components in the phases of sepsis.

\section{RECENT ADVANCES OF PURINERGIC SIGNALING IN SEPSIS}

In recent years, studies have demonstrated the involvement of purinergic signaling in the pathophysiology of sepsis. ATP exerts a pro-inflammatory response in macrophages, monocytes, and dendritic cells, promoting pro-inflammatory cytokine release (i.e., IL-1 $\beta$ and IL-18) (Grahames et al., 1999; Ferrari et al., 2007), while adenosine stimulates the release of antiinflammatory cytokines (i.e., IL-10) (Németh et al., 2005). In addition, eATP levels increase neutrophil migration and activation, causing tissue damage and organ injury (Sumi et al., 2014). The P2X7 receptor (P2X7R) has been described as the most relevant purinergic receptor involved in inflammatory processes (Di Virgilio and Pelegrín, 2019). This receptor is widely expressed by immune cells and it mediates the activation of several inflammatory and antimicrobial mechanisms in infection diseases, including sepsis (reviewed in Savio et al., 2018).

P2X7R gain-of-function single nucleotide polymorphisms have been correlated to increase sepsis severity in humans (Geistlinger et al., 2012). A recent study found P2X7R expression is elevated in the surface of monocytes from patients with sepsis. Moreover, cytokine levels (e.g., those of IL-1 $\beta$, IL-18), the alarmin HMGB1, and ASC aggregates are increased in the serum of these patients (Martínez-García et al., 2019). These findings suggest the involvement of the P2X7-NLRP3 axis in sepsis (Martínez-García et al., 2019). P2X7R pharmacological blockade with BBG decreased levels of inflammatory cytokines (i.e., IL-1 $\beta$, IL-6, and IL-10), NO production, and neutrophil recruitment to the peritoneal cavity in a mouse model of sepsis. This inhibition decreased liver damage and attenuated activation of inflammatory signaling pathways, demonstrating the protective effect of P2X7R inhibition in the initial phase of sepsis (Savio et al., 2017b). Similarly, genetic deletion of P2X7R or treatment with the antagonist A438079 decreased the mortality rate in sepsis induced by cecal ligation and puncture (CLP) (Santana et al., 2015; Wang et al., 2015). Corroborating these data, P2X7R activation by BzATP promoted excessive inflammation and disruption of the intestinal barrier, while systemic blockade using P2X7 antagonist A740003 protected mice against sepsis (Wu et al., 2017). P2X7R is also directly connected to oxidative stress and pro-inflammatory cytokines secretion in the liver (Larrouyet-Sarto et al., 2020) and brain of septic mice (Savio et al., 2017a). Interestingly, these effects are tightly restrained by CD39 activity (Savio et al., 2017a).

Di Virgilio and Pelegrín reported that, even though the P2X7R has been described as the purinergic receptor most involved in inflammatory processes, recent findings suggest that P2X4 receptor (P2X4R) exhibits relevant contributions in this context as well (Di Virgilio and Pelegrín, 2019). Csoka and colleagues showed that ATP is responsible for Escherichia coli and Staphylococcus aureus killing in wild-type macrophages, and this effect is independent of P2X7Rs (Csóka et al., 2018). Using $\mathrm{CD}_{3} 9^{-1-}$ mice, they demonstrated that adenosine was not responsible for bacterial killing. In addition, they showed that ATP failed to destroy these pathogens in macrophages isolated from $\mathrm{P} 2 \mathrm{X} 4^{-/-}$mice. P2X4 expression levels were elevated in liver and lung of septic mice. By contrast, in peritoneal monocytes/ macrophages and neutrophils, expression levels were decreased, suggesting that, in the CLP model, P2X4R has a protective role (Csóka et al., 2018).

Another purinergic receptor that may have a role in sepsis pathogenesis is $\mathrm{P} 2 \mathrm{X} 1$ (P2X1R). In a model of urosepsis using an E. coli strain, the inhibition of this receptor with two different antagonists (NF279 and NF449) showed that this receptor could not protect the host against sepsis. P2X1R antagonism promoted an increased pro-inflammatory cytokine release (i.e., IL-1 $\beta$, TNF$\alpha$, and IL-6) and higher bacterial load, decreasing survival in mice (Skals et al., 2019).

Despite the importance of $\mathrm{P} 2 \mathrm{X}$ receptors, $\mathrm{P} 2 \mathrm{Y}$ receptors can also be relevant in sepsis. Interestingly, a recent report demonstrated that eATP increased in the peritoneal cavity and systemic circulation of mice subjected to the CLP model. This increase was confirmed using LPS-primed peritoneal macrophages that showed a connexin-43-dependent pathway for ATP release. This nucleotide acts through in autocrine manner, activating $\mathrm{P}_{2} \mathrm{Y}_{1}$ receptor and then inducing the release of pro-inflammatory cytokines (Dosch et al., 2019). Accordingly, LPS-stimulated monocytes release ATP that can suppress $\mathrm{T}$ cell responses. eATP can activate the $\mathrm{P} 2 \mathrm{Y}_{11}$ receptor, which impairs mitochondrial activity and blocks $\mathrm{T}$ cell migration required for host defense in sepsis (Sueyoshi et al., 2019). Furthermore, the $\mathrm{P}_{2} \mathrm{Y}_{12}$ antagonist (clopidogrel) reduced the number of white blood cells (WBCs), including lymphocytes and neutrophils in septic mice. Clopidogrel also significantly reduced sepsis-induced lung injury. $\mathrm{P}_{2} \mathrm{Y}_{12}$ receptor-deficient mice also showed diminished production of inflammatory mediators (i.e., IL-6, TNF- $\alpha$, IL-10, and MIP-1) and reduced sepsis-induced lung injury (Liverani et al., 2016).

An important mechanism that can protect against sepsis are the activities of the ectoenzymes E-NTPDase1/CD39 and ecto-5' nucleotidase/CD73, which are responsible for catalyzing the degradation of ATP to adenosine. Ectonucleotidase activities increased in lymphocytes and macrophages from septic mice (Vuaden et al., 2011; Savio et al., 2017b). CD39 diminished the inflammation and enhanced the survival of septic mice due to its ability to scavenge eATP (Csóka et al., 2015). CD39 is essential to limit P2X7R pro-inflammatory effects in sepsis (Csóka et al., 
2015; Savio et al., 2017b). Moreover, CD39 overexpression inhibited the NLRP3 inflammasome activation, which decreased inflammation and mitigated sepsis-induced organ injury (Yang et al., 2019). CD73 deficiency also decreased survival, bacterial clearance, and increased cytokine and chemokine production in CLP-induced sepsis (Haskó et al., 2011). These reports demonstrate the crucial role of these enzymes in protecting against inflammation and host organ injury in the initial stages of sepsis, because they promote adenosine formation in the extracellular milieu. However, adenosine generated by these enzymes may contribute to cellular reprogramming and development of immunosuppression in the latter stages of sepsis.

Adenosine receptors have also been studied in sepsis, especially $\mathrm{A}_{2 \mathrm{~A}}$ and $\mathrm{A}_{2 \mathrm{~B}}$ (Rehman et al., 2020). In a mouse model of endotoxemia, pharmacological activation of $A_{2 A}$ receptor improved survival rates and reduced bacteremia (Sullivan et al., 2004). A similar protective profile in septic mice treated with $\mathrm{A}_{2 \mathrm{~A}}$ agonists was observed when mice were infected with gram-positive and gram-negative bacteria, including an increase of anti-inflammatory and decreased proinflammatory cytokines (Moore et al., 2008). Nevertheless, $A_{2 A}$ stimulation can be ambiguous in a polymicrobial infection. In a peritonitis model caused by the injection of a fecal solution, survival was higher and bacterial load was lower in $\mathrm{A}_{2 \mathrm{~A}}$-deficient animals (Meriño et al., 2020). In CLP-induced sepsis, $A_{2 A}$ knockout or antagonism likewise enhanced survival, in addition to attenuating anti-inflammatory cytokines levels and bacterial burden in serum and peritoneal lavage fluid (Németh et al., 2008). Conflicting results were obtained in studies regarding the $A_{2 B}$ receptor in sepsis. Genetic deletion or pharmacological blockade decreased mortality rates by increasing active macrophage phagocytosis and bacterial clearance (Belikoff et al., 2011). By contrast, another study using the same polymicrobial infection model and the same approaches, including the antagonist used, resulted in a higher mortality rate (Csóka et al., 2010).

Interestingly, combined approaches appear to be beneficial in the initial stages of CLP-induced sepsis. Combined $\mathrm{A}_{2 \mathrm{~A}}$ activation and P2X7 inhibition decreased hepatic cell death liver injury, demonstrating the relevance of CD39 activity for restricting proinflammatory mechanisms and providing substrates for CD73, thereby providing adenosine in the extracellular milieu (Savio et al., 2017b). Indeed, in a study regarding septic cardiomyopathy, septic mice showed diminished ischemia and reperfusion injury, presumably mediated by upregulation of both $\mathrm{A}_{2 \mathrm{~A}}$ and $\mathrm{A}_{2 \mathrm{~B}}$ expression in ventricles, as their blockade essentially abolished this cardioprotective effect (Busse et al., 2016). Finally, $A_{1}$ receptor antagonism, genetic ablation, and desensitization were all associated with lymphopenia, a clinical feature of sepsis that correlates with more significant lethality (Riff et al., 2017).

\section{CONCLUSION AND FUTURE DIRECTIONS}

Sepsis is a complex and uncontrolled systemic inflammation caused by pathogen infection. Usually, sepsis is caused by bacteria; nevertheless, some viruses can also induce systemic inflammatory responses, including the recently described severe acute respiratory syndrome coronavirus 2 (SARS-Cov2) (Li et al., 2020). Interestingly, purinergic signaling is also potentially involved in the pathogenesis of SARS-Cov2, considering its role in IL- $1 \beta$ secretion (Di Virgilio et al., 2020). Recently, Huet and colleagues showed that a human IL-1 receptor antagonist (anakinra) improved outcomes and decreased mortality among patients with severe forms of SARS-Cov2 (Huet et al., 2020).

Sepsis is a dynamic syndrome that can be divided into two phases. The first one is commonly known as an intense inflammatory phase, and the second is associated with an immunosuppressive state, which refers to lymphocyte exhaustion and immune cell reprogramming. Considering the high costs to the health systems, the difficulty of managing sepsis, and the consequences for patients who survive and develop longterm sequelae, it is imperative to identify new therapies to improve these outcomes. Therefore, even though antibiotic treatment is the primary approach in sepsis, new procedures are necessary to prevent adjacent immune abnormalities caused by this disease. Interventions targeting purinergic signaling components could be interesting adjuvant therapies.

The severity and the phases of sepsis should be considered to develop therapeutical strategies based on purinergic signaling. According to the studies discussed here, P2 receptors, mainly $\mathrm{P} 2 \mathrm{X} 4$ and $\mathrm{P} 2 \mathrm{X} 7$ receptors, were able to activate microbicidal mechanisms and induce pro-inflammatory cytokines release, which can be necessary for pathogen control, but at the same time can be related to the initial hyperinflammatory phase of sepsis, causing organ dysfunction and poor outcomes. On the other hand, adenosine, acting mainly via $\mathrm{A}_{2 \mathrm{~A}}$ and $\mathrm{A}_{2 \mathrm{~B}}$ receptors, may promote anti-inflammatory cytokines release and attenuate tissue injury, suggesting a protective role in initial sepsis phases. Nevertheless, adenosine-based interventions should be carefully analyzed. This molecule can contribute to the reprogramming of immune cells to an immunosuppressive phenotype, causing secondary infections and long-term sequelae.

A limiting mechanism in this context is the functionality of ectoenzymes CD39/CD73 that are essential for the degradation of ATP into adenosine, contributing to the switch between proinflammatory and anti-inflammatory responses in sepsis (Figure 1). Therefore, the CD39/CD73 axis appears to be protective in the initial phase of sepsis, reducing the excessive inflammation. Nevertheless, the increased expression of these enzymes by immune cells and the continuous adenosine generation during the disease progression may also contribute to immunosuppression and late sequelae.

Therefore, the use of $\mathrm{P} 2$ receptor antagonists and soluble apyrases may be an attractive therapeutic approach in association with antibiotics to dampen excessive inflammation and control infection in the initial phase of sepsis. In addition, natural polyphenolic compounds have shown anti-inflammatory properties by inhibiting ATP-P2X7 signaling (Nuka et al., 2018). In the second phase of sepsis, the administration of adenosine antagonists and CD39/CD73 neutralizing antibodies could limit the immunosuppression, reducing the susceptibility to secondary infections and late metabolic and immune alterations (Figure 1). 


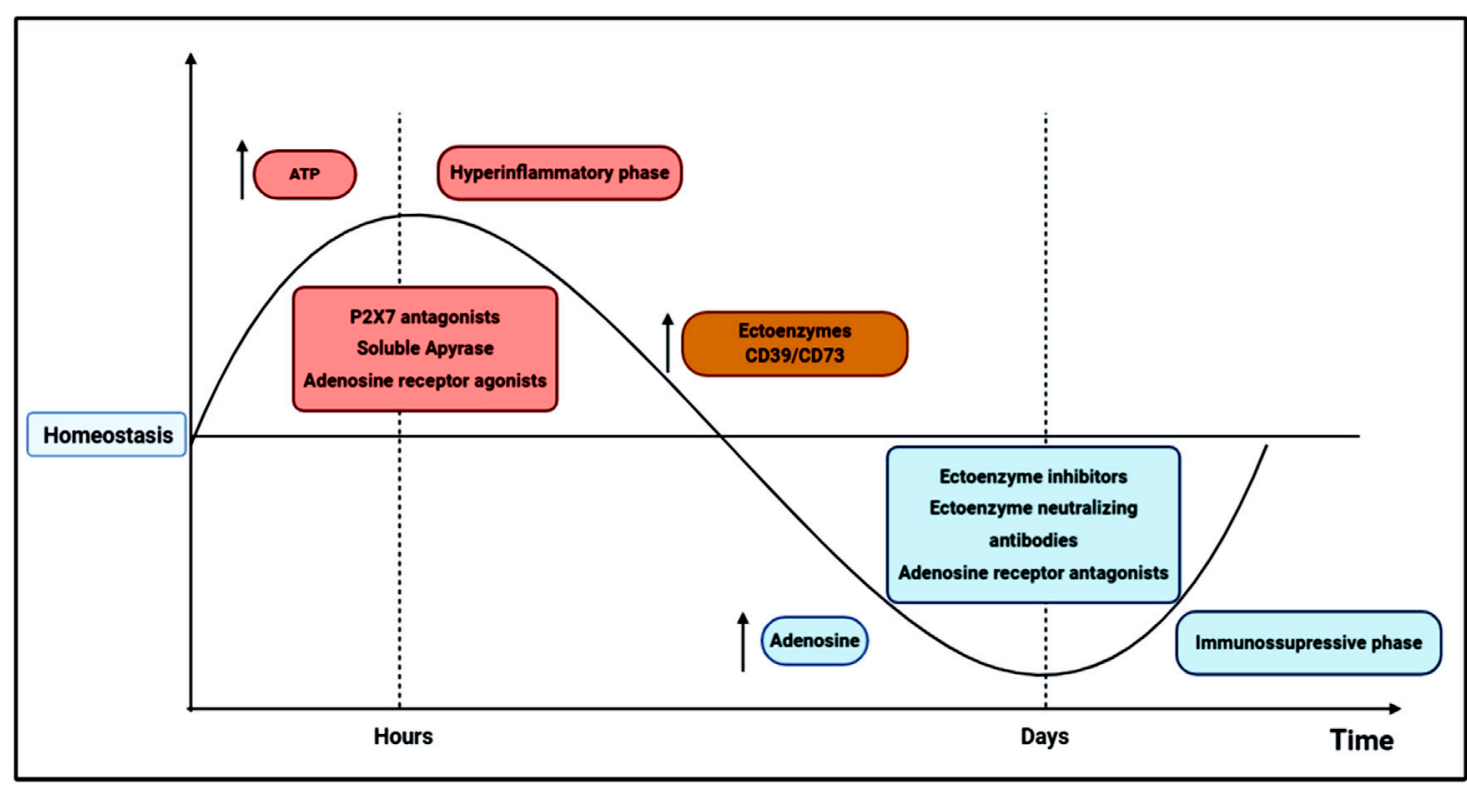

FIGURE 1 | Schematic representation of possible therapeutic interventions based on purinergic signaling components in sepsis dynamics. In the first $24-72 \mathrm{~h}$, sepsis pathogenesis is characterized by excessive innate and adaptive immune responses, in which high levels of cytokines and other inflammatory mediators are produced, inducing organ dysfunction and ultimately, a high mortality rate. This initial hyperinflammatory phase (in red) can be modulated by ATP secretion from activated and damaged cells. ATP activates P2 receptors involved in pro-inflammatory reactions, such as the P2X7 receptor, which has been related to poor outcomes in sepsis. Thus, the administration of P2X7 antagonists has been described as a potential therapeutic target in the initial phase sepsis, reducing inflammatory cytokines release, tissue damage and mortality. Adenosine is commonly associated with inflammation control and tissue protection; therefore, adenosine agonists and soluble ectoenzymes may also represent interesting therapeutic strategies to control the initial hyperinflammatory phase. After some days of disease progression, a secondary state arises where a diminished cytokine secretion is verified, and inflammatory cells are directed to an apoptotic or reprogrammed state, which in turn may lead to an immunosuppressive phase (in blue), where opportunistic infections are most likely to occur increasing mortality. In the transition from hyper-to a hypoinflammatory phase, ectoenzyme activities, and adenosine availability increase in the extracellular milieu, possibly favoring cellular reprogramming and immunosuppression development. Therefore, in the second stage of sepsis, P1 receptor antagonists and CD39/CD73 neutralizing antibodies or inhibitors could restrain the immunosuppressive state, reducing host susceptibility to secondary infections and late metabolic and immune alterations.

Future studies should consider these observations for the development of adjuvant therapies based on purinergic signaling to manage the immune environment in sepsis.

\section{AUTHOR CONTRIBUTIONS}

RL-A, and VA drafted the manuscript. LS and RC-S contributed to writing and editing.

\section{REFERENCES}

Alves, V. S., Leite-Aguiar, R., da Silva, J. P., Coutinho-Silva, R., and Savio, L. E. B. (2020). Purinergic signaling in infectious diseases of the central nervous system. Brain Behav. Immun. 89, 480-490. doi:10.1016/j.bbi.2020.07.026

Antonioli, L., Blandizzi, C., Fornai, M., Pacher, P., Lee, H. T., and Haskó, G. (2019). P2X4 receptors, immunity, and sepsis. Curr. Opin. Pharmacol. 47, 65-74. doi:10.1016/j.coph.2019.02.011

Belikoff, B. G., Hatfield, S., Georgiev, P., Ohta, A., Lukashev, D., Buras, J. A., et al. (2011). A2B adenosine receptor blockade enhances macrophage-mediated bacterial phagocytosis and improves polymicrobial sepsis survival in mice. J. Immunol. 186, 2444-2453. doi:10.4049/jimmunol.1001567

\section{FUNDING}

This work was supported by funds from the Conselho Nacional de Desenvolvimento Cientifico e Tecnológico do Brasil-CNPq (306839/2019-9 to RC-S), Coordenação de Aperfeiçoamento de Pessoal de Nível Superior (CAPES), and Fundação de Amparo à Pesquisa do Estado do Rio de Janeiro-FAPERJ (E-26/202.701/ 2019 and E-26/010.002260/2019 to LS; 26/010.101036/2018 and E-26/202.774/2018 to RC-S).

Boomer, J. S., To, K., Chang, K. C., Takasu, O., Osborne, D. F., Walton, A. H., et al. (2011). Immunosuppression in patients who die of sepsis and multiple organ failure. JAMA. 306, 2594-2605. doi:10.1001/jama.2011.1829

Burnstock, G., and Verkhratsky, A. (2009). Evolutionary origins of the purinergic signalling system. Acta. Physiol. 195, 415-447. doi:10.1111/j.1748-1716.2009. 01957.x

Busse, H., Bitzinger, D., Höcherl, K., Seyfried, T., Gruber, M., Graf, B. M., et al. (2016). Adenosine A2A and A2B receptor substantially attenuate ischemia/ reperfusion injury in septic rat hearts. Cardiovasc. Drugs Ther. 30, 551-558. doi:10.1007/s10557-016-6693-y

Cauwels, A., Rogge, E., Vandendriessche, B., Shiva, S., and Brouckaert, P. (2014). Extracellular ATP drives systemic inflammation, tissue damage and mortality. Cell Death Dis. 5, e1102. doi:10.1038/cddis.2014.70 
Cavaillon, J., Singer, M., and Skirecki, T. (2020). Sepsis therapies: learning from 30 years of failure of translational research to propose new leads. EMBO Mol. Med. 12, e10128. doi:10.15252/emmm.201810128

Coutinho-Silva, R., and Ojcius, D. M. (2012). Role of extracellular nucleotides in the immune response against intracellular bacteria and protozoan parasites. Microbes Infect. 14, 1271-1277. doi:10.1016/j.micinf.2012.05.009

Csóka, B., Németh, Z. H., Rosenberger, P., Eltzschig, H. K., Spolarics, Z., Pacher, P., et al. (2010). A2B adenosine receptors protect against sepsis-induced mortality by dampening excessive inflammation. J. Immunol. 185, 542-550. doi:10.4049/jimmunol.0901295

Csóka, B., Németh, Z. H., Szabó, I., Davies, D. L., Varga, Z. V., Pálóczi, J., et al. (2018). Macrophage P2X4 receptors augment bacterial killing and protect against sepsis. JCI Insight. 3, e99431. doi:10.1172/jci.insight.99431

Csóka, B., Németh, Z. H., Töro, G., Koscsó, B., Kókai, E., Robson, S. C., et al. (2015). CD39 improves survival in microbial sepsis by attenuating systemic inflammation. FASEB J. 29, 25-36. doi:10.1096/fj.14-253567

Di Virgilio, F., and Pelegrín, P. (2019). Editorial overview: purinergic P2X receptors in innate immunity and inflammation. Curr. Opin. Pharmacol. 47, 141-144. doi:10.1016/j.coph.2019.05.003

Di Virgilio, F., Tang, Y., Sarti, A. C., and Rossato, M. (2020). A rationale for targeting the P2X7 receptor in Coronavirus disease 19. Br. J. Pharmacol. 177, 4990-4994. doi:10.1111/bph.15138

Dosch, M., Zindel, J., Jebbawi, F., Melin, N., Sanchez-Taltavull, D., Stroka, D., et al. (2019). Connexin-43-dependent ATP release mediates macrophage activation during sepsis. Elife. 8, e42670. doi:10.7554/eLife.42670

Ferrari, D., Gorini, S., Callegari, G., and la Sala, A. (2007). Shaping immune responses through the activation of dendritic cells' P2 receptors. Purinergic Signal. 3, 99-107. doi:10.1007/s11302-006-9024-0

Fredholm, B. B., IJzerman, A. P., Jacobson, K. A., Linden, J., and Müller, C. E. (2011). International union of basic and clinical pharmacology. LXXXI. Nomenclature and classification of adenosine receptors-an update. Pharmacol. Rev. 63, 1-34. doi:10.1124/pr.110.003285

Geistlinger, J., Du, W., Groll, J., Liu, F., Hoegel, J., Foehr, K. J., et al. (2012). P2RX7 genotype association in severe sepsis identified by a novel multi-individual array for rapid screening and replication of risk SNPs. Clin. Chim. Acta. 413, 39-47. doi:10.1016/j.cca.2011.05.023

Grahames, C. B. A., Michel, A. D., Chessell, I. P., and Humphrey, P. P. A. (1999). Pharmacological characterization of ATP- and LPS-induced IL-1 $\beta$ release in human monocytes. Br. J. Pharmacol. 127, 1915-1921. doi:10.1038/sj.bjp.0702732

Haskó, G., Csóka, B., Koscsó, B., Chandra, R., Pacher, P., Thompson, L. F., et al. (2011). Ecto-5'-Nucleotidase (CD73) decreases mortality and organ injury in sepsis. J. Immunol. 187, 4256-4267. doi:10.4049/jimmunol.1003379

Hotchkiss, R. S., Monneret, G., and Payen, D. (2013a). Immunosuppression in sepsis: a novel understanding of the disorder and a new therapeutic approach. Lancet Infect. Dis. 13, 260-268. doi:10.1016/S1473-3099(13)70001-X.Immunosuppression

Hotchkiss, R. S., Monneret, G., and Payen, D. (2013b). Sepsis-induced immunosuppression: from cellular dysfunctions to immunotherapy. Nat. Rev. Immunol. 13, 862-874. doi:10.1038/nri3552

Huet, T., Beaussier, H., Voisin, O., Jouveshomme, S., Dauriat, G., Lazareth, I., et al. (2020). Anakinra for severe forms of COVID-19: a cohort study. Lancet Rheumatol. 2, 393-400. doi:10.1016/S2665-9913(20)30164-8

Idzko, M., Ferrari, D., and Eltzschig, H. K. (2014). Nucleotide signalling during inflammation. Nature. 509, 310-317. doi:10.1038/nature13085

Jacobson, K. A., Delicado, E. G., Gachet, C., Kennedy, C., von Kügelgen, I., Li, B., et al. (2020). Update of P2Y receptor pharmacology: IUPHAR review 27. Br. J. Pharmacol. 177, 2413-2433. doi:10.1111/bph.15005

Larrouyet-Sarto, M. L., Tamura, A. S., Alves, V. S., Santana, P. T., Ciarlinimagalhães, R., Rangel, T. P., et al. (2020). P2X7 receptor deletion attenuates oxidative stress and liver damage in sepsis. Purinergic Signal. doi:10.1007/ s11302-020-09746-7

Ledderose, C., Bao, Y., Kondo, Y., Fakhari, M., Slubowski, C., Zhang, J., et al. (2016). Purinergic signaling and the immune response in sepsis: a review. Clin. Ther. 38, 1054-1065. doi:10.1016/j.clinthera.2016.04.002

Li, H., Liu, L., Zhang, D., Xu, J., Dai, H., Tang, N., et al. (2020). SARS-CoV-2 and viral sepsis: observations and hypotheses. Lancet. 395, 1517-1520. doi:10.1016/ S0140-6736(20)30920-X

Liverani, E., Rico, M. C., Tsygankov, A. Y., Kilpatrick, L. E., and Kunapuli, S. P. (2016). P2Y12 receptor modulates sepsis-induced inflammation. Arterioscler. Thromb. Vasc. Biol. 36, 961-971. doi:10.1161/ATVBAHA.116.307401
Ma, K. C., Schenck, E. J., Pabon, M. A., and Choi, A. M. K. (2018). The role of danger signals in the pathogenesis and perpetuation of critical illness. Am. J. Respir. Crit. Care Med. 197, 300-309. doi:10.1164/rccm.201612-2460PP

Martínez-García, J. .., Martínez-Banaclocha, H., Angosto-Bazarra, D., de Torre-Minguela, C., Baroja-Mazo, A., Alarcón-Vila, C., et al. (2019). P2X7 receptor induces mitochondrial failure in monocytes and compromises NLRP3 inflammasome activation during sepsis. Nat. Commun. 10, 2711. doi:10.1038/s41467-019-10626-x

Meriño, M., Martín, S. S., Sandaña, P., Herlitz, K., Aguayo, C., Godoy, A., et al. (2020). Deletion of the adenosine A2A receptor increases the survival rate in a mice model of polymicrobial sepsis. Purinergic Signal. 16 (3), 427-437. doi:10. 1007/s11302-020-09719-w

Moore, C. C., Martin, E. N., Lee, G. H., Obrig, T., Linden, J., and Michael, W. M. (2008). An A2A adenosine receptor agonist, ATL313, reduces inflammation and improves survival in murine sepsis models. BMC Infect. Dis. 8, 1-10. doi:10. 1186/1471-2334-8-141

Németh, Z. H., Csóka, B., Wilmanski, J., Xu, D., Lu, Q., Ledent, C., et al. (2008). Adenosine A2A receptor inactivation increases survival in polymicrobial sepsis. J. Immunol. 176, 5616-5626. doi:10.4049/jimmunol.176.9.5616

Németh, Z. H., Lutz, C. S., Csóka, B., Deitch, E. A., Leibovich, S. J., Gause, W. C., et al. (2005). Adenosine augments IL-10 production by macrophages through an A $2 \mathrm{~B}$ receptor-mediated posttranscriptional mechanism. J. Immunol. 175, 8260-8270. doi:10.4049/jimmunol.175.12.8260

Nuka, E., Ohnishi, K., Terao, J., and Kawai, Y. (2018). ATP/P2X7 receptor signaling as a potential anti-inflammatory target of natural polyphenols. PLoS One. 13, 1-19. doi:10.1371/journal.pone.0204229

Otto, G. P., Sossdorf, M., Claus, R. A., Rödel, J., Menge, K., Reinhart, K., et al. (2011). The late phase of sepsis is characterized by an increased microbiological burden and death rate. Crit. Care. 15, R183. doi:10.1186/cc10332

Ralevic, V., and Burnstock, G. (1998). Receptors for purines and pyrimidines. Pharmacol. Rev. 50, 413-492.

Rehman, A., Baloch, N. U. A., Morrow, J. P., Pacher, P., and Haskó, G. (2020). Targeting of G-protein coupled receptors in sepsis. Pharmacol. Ther. 211, 107529. doi:10.1016/j.pharmthera.2020.107529

Reinhart, K., Daniels, R., Kissoon, N., Machado, F. R., Schachter, R. D., and Finfer, S. (2017). Recognizing sepsis as a global health priority-a WHO resolution. $N$. Engl. J. Med. 377, 414-417. doi:10.1056/NEJMp1704633

Riff, R., Cohen, Y., Eini-Rider, H., Naamani, O., Mazar, J., Haviv, Y. S., et al. (2017). Systemic inflammatory response syndrome-related lymphopenia is associated with adenosine A 1 receptor dysfunction. J. Leukoc. Biol. 102, 95-103. doi:10. 1189/jlb.3a0816-345rr

Robson, S. C., Sévigny, J., and Zimmermann, H. (2006). The E-NTPDase family of ectonucleotidases: structure function relationships and pathophysiological significance. Purinergic Signal. 2, 409-430. doi:10. 1007/s11302-006-9003-5

Rudd, K. E., Johnson, S. C., Agesa, K. M., Shackelford, K. A., Tsoi, D., Kievlan, D. R., et al. (2020). Global, regional, and national sepsis incidence and mortality, 1990-2017: analysis for the global burden of disease study. Lancet. 395, 200-211. doi:10.1016/S0140-6736(19)32989-7

Santana, P. T., Benjamim, C. F., Martinez, C. G., Kurtenbach, E., Takiya, C. M., and Coutinho-Silva, R. (2015). The P2X7 receptor contributes to the development of the exacerbated inflammatory response associated with sepsis. J. Innate Immun. 7, 417-427. doi:10.1159/000371388

Savio, L. E. B., Andrade, M. G. J., de Andrade Mello, P., Santana, P. T., Moreira-Souza, A. C. A., Kolling, J., et al. (2017a). P2X7 receptor signaling contributes to sepsis-associated brain dysfunction. Mol. Neurobiol. 54, 6459-6470. doi:10.1007/s12035-016-0168-9

Savio, L. E. B., de Andrade Mello, P., Figliuolo, V. R., de Avelar Almeida, T. F., Santana, P. T., Oliveira, S. D. S., et al. (2017b). CD39 limits P2X7 receptor inflammatory signaling and attenuates sepsis-induced liver injury. J. Hepatol. 67, 716-726. doi:10.1016/j.jhep.2017.05.021

Savio, L. E. B., and Coutinho-Silva, R. (2019). Immunomodulatory effects of P2X7 receptor in intracellular parasite infections. Curr. Opin. Pharmacol. 47, 53-58. doi:10.1016/j.coph.2019.02.005

Savio, L. E. B., de Mello, P. A., da Silva, C. G., and Coutinho-Silva, R. (2018). The P2X7 receptor in inflammatory diseases: angel or demon? Front. Pharmacol. 9, 52. doi:10.3389/fphar.2018.00052

Singer, M., Deutschman, C. S., Seymour, C., Shankar-Hari, M., Annane, D., Bauer, M., et al. (2016). The third international consensus definitions for sepsis and septic shock (sepsis-3). JAMA. 315, 801-810. doi:10.1001/jama.2016.0287 
Skals, M., Greve, A. S., Fagerberg, S. K., Johnsen, N., Christensen, M. G., and Praetorius, H. A. (2019). P2X1 receptor blockers reduce the number of circulating thrombocytes and the overall survival of urosepsis with haemolysin-producing Escherichia coli. Purinergic Signal. 15, 265-276. doi:10.1007/s11302-019-09658-1

Sueyoshi, K., Ledderose, C., Shen, Y., Lee, A. H., Shapiro, N. I., and Junger, W. G. (2019). Lipopolysaccharide suppresses T cells by generating extracellular ATP that impairs their mitochondrial function via P2Y11 receptors. J. Biol. Chem. 294, 6283-6293. doi:10.1074/jbc.RA118.007188

Sullivan, G. W., Fang, G., Linden, J., and Scheld, W. M. (2004). A2A adenosine receptor activation improves survival in mouse models of endotoxemia and sepsis. J. Infect. Dis. 189, 1897-1904. doi:10.1086/386311

Sumi, Y., Woehrle, T., Chen, Y., Bao, Y., Li, X., Yao, Y., et al. (2014). Plasma ATP is required for neutrophil activation in a mouse sepsis model. Shock. 42, 142-147. doi:10.1097/SHK.0000000000000180

Van Der Poll, T., Van De Veerdonk, F. L., Scicluna, B. P., and Netea, M. G. (2017). The immunopathology of sepsis and potential therapeutic targets. Nat. Rev. Immunol. 17, 407-420. doi:10.1038/nri.2017.36

Vuaden, F. C., Savio, L. E. B., Bastos, C. M. A., Bogo, M. R., and Bonan, C. D. (2011). Adenosine A2A receptor agonist (CGS-21680) prevents endotoxininduced effects on nucleotidase activities in mouse lymphocytes. Eur. J. Pharmacol. 651, 212-217. doi:10.1016/j.ejphar.2010.11.003

Wang, H., Hong, L. J., Huang, J. Y., Jiang, Q., Tao, R. R., Tan, C., et al. (2015). P2RX 7 sensitizes Mac-1/ICAM-1-dependent leukocyte-endothelial adhesion and promotes neurovascular injury during septic encephalopathy. Cell Res. 25, 674-690. doi:10.1038/cr.2015.61

Wiersinga, W. J., Leopold, S. J., Cranendonk, D. R., and van der Poll, T. (2014). Host innate immune responses to sepsis. Virulence. 5, 36-44. doi:10.4161/viru. 25436

Wu, X., Ren, J., Chen, G., Wu, L., Song, X., Li, G., et al. (2017). Systemic blockade of $\mathrm{P} 2 \mathrm{X} 7$ receptor protects against sepsis-induced intestinal barrier disruption. Sci. Rep. 7, 4364. doi:10.1038/s41598-017-04231-5

Yang, M., Lu, L., Kang, Z., Ma, T., and Wang, Y. (2019). Overexpressed CD39 mitigates sepsis-induced kidney epithelial cell injury via suppressing the activation of NLR family pyrin domain containing 3. Int. J. Mol. Med. 44, 1707-1718. doi:10.3892/ijmm.2019.4349

Conflict of Interest: The authors declare that the research was conducted in the absence of any commercial or financial relationships that could be construed as a potential conflict of interest.

Copyright (c) 2021 Leite-Aguiar, Alves, Savio and Coutinho-Silva. This is an openaccess article distributed under the terms of the Creative Commons Attribution License (CC BY). The use, distribution or reproduction in other forums is permitted, provided the original author(s) and the copyright owner(s) are credited and that the original publication in this journal is cited, in accordance with accepted academic practice. No use, distribution or reproduction is permitted which does not comply with these terms. 